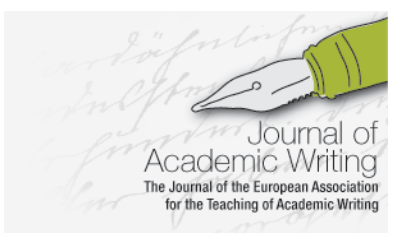

Journal of Academic Writing Vol. 11 No 1 Summer 2021, pages 80-91 https://doi.org/10.18552/joaw.v11i1.423

\title{
The Efficacy of Short Pre-sessional Courses on Learner Writing
}

Marcus Bridle

Waseda University

\begin{abstract}
This study examines the development of learner written accuracy over the course of a short, university pre-sessional course. One of the issues practitioners and learners are faced with on short courses is the time limitation, which can result in an emphasis on the macros-linguistic, organisational features of academic writing at the expense of a focus on written accuracy. The research charted the effects of an error feedback and revision cycle on student writing. The key observations were that the majority of revisions were made successfully and that this may have contributed towards the subsequent written accuracy of drafts. These findings suggest that, contrary to some perceptions, short pre-sessional courses can have a positive effect on the linguistic accuracy of learner writing.
\end{abstract}

\section{Introduction}

For over a decade, the number of international students completing degree courses at Higher Education (HE) institutions in the UK has been increasing (Alexander et al., 2008; DfBIS, 2013). Even in the context of the numerous insecurities around student numbers caused by the UK leaving the EU, the trend is likely to continue and numbers of foreign students will probably remain high; $14 \%$ of all HE students in the UK are currently from non-EU countries and China alone accounts for a third of these (HESA, 2019). Non-native speaker students are required to demonstrate a suitable level of English in order to join their degree programs and as such, enrolment of pre-sessional English preparatory courses is often required. These programs have, in fact, become almost de-rigeur at British universities (Archibald, 2001; Alexander et al., 2008; Hyland, 2009). Courses meet the learner need for familiarisation with the conventions of English for Academic Purposes (EAP) and fulfil an important administrative role for both the HE institutions and the UK Border Agency (UKBA) in ensuring that non-native speakers have a level of English which is adequate for study (Banarjee \& Wall, 2006, p. 50). This continued rise in the number of international students and the resulting proliferation of pre-sessional courses means there is a complimentary growth in the need for an understanding of exactly how English courses are providing for learners.

This observational study investigates some of the outcomes of what might be regarded as a typical, intensive pre-sessional course. Specifically, it examines a common draft-feedbackrevision cycle and its effect upon the writing accuracy. Writing is, with most courses, likely to be both an important area of course assessment but also the skill area in which many students have to develop the most in order to be successful in future academic environments (Alexander et al., 2008). The findings suggest that concerns about the difficulty of addressing accuracy of language production within a short pre-sessional course can to some extent be addressed through a feedback mechanism.

\subsection{The nature of pre-sessional courses}

Pre-sessional courses can vary in length, sometimes being a full academic year in length, but many are described as 'intensive' and are of four to sixteen weeks in length, typically occurring over the summer before the British academic year begins. The length and intensity of these 
courses results in complications for instructors and students alike. The time factor means it is difficult to teach or learn at a pace natural to the students. Syllabus design is also restricted and covering all areas and needs is problematic. Even the eventual learning aims of the courses can be difficult to establish; they could be for learners to become familiar with the general elements of EAP, or the conventions of a particular subject area, or simply to pass an exit exam providing a score meeting the conditions of a departmental offer. On many courses, the aims will be a mix of these and more.

The obvious challenges of catering to a wide range of needs means that many pre-sessional courses are alike in providing a structure which covers academic English in as broad a way as possible. This necessitates adopting a 'wide-angle' approach (Widdowson, 1983, p. 6), which covers a number of general functions. In terms of writing, this often means an emphasis on the rhetorical features of particular genres and which can be taught to students on a whole-class basis (Swales, 2005; Bruce, 2011). This may involve instruction of specific linguistic elements such as cohesive devices, but these are likely to be covered as part of a more general focus on patterns of organisation and discourse. Input on cause and effect language may, for example, occur within the context of developing a problem-solution style essay whilst practice in the passive voice is tied to the function of describing a process, as in Hamp-Lyons and Heasley (2006).

At the same time as these generic writing components are covered, pre-sessional courses are often also tasked with inducting learners new to academia itself with the fundamental skills and conventions associated with academic English such as critical reading, paraphrasing, citing and referencing. Further is the inherent drive of most institutions and instructors towards encouraging students to develop cultural awareness and independent learning skills which will equip them for study on their degree courses (Watson-Todd, 2003; Alexander et al., 2008; Gillett, 2011).

Whilst this approach may be the most pragmatic, its critics argue that it may compromise the development of learner linguistic ability. Archibald (2001), for example, investigated the effects of a pre-sessional course on written proficiency. He employed seven traits to analyse texts which were produced and, notably, only two of these related directly to the language itself, as opposed to the structure of the language. These were (i) linguistic accuracy (grammar, spelling and punctuation which did not impede communication) and (ii) linguistic appropriacy. Over the course of eight weeks, these areas were shown to have statistically less likelihood of tangible improvement. Likewise, Cho (2003) found that linguistic accuracy was less likely than any other factor to show any kind of improvement after a period of instruction. That linguistic improvement has not been consistently observed may have led to attitudes like those described by Basturkmen and Lewis (2002) becoming firmly rooted amongst instructors and institutions. They reported that teachers administering a twelve-week pre-sessional course regarded improvement in grammatical accuracy and linguistic proficiency as unrealistic. Therefore, the broader organisational elements were emphasised. This is perhaps understandable given the time frame these courses are conducted in and particularly so when one considers the observations Banarjee and Wall (2006) make about departmental supervisors placing a value on content and accurate referencing rather than accurate production of language.

One issue with what seems to be the prevailing attitude amongst instructors is that it is often directly at odds with the students' perception of their needs. These tend to be linguistic in nature (Burgess \& Etherington, 2002) and Hartshorn et al. (2010) have noted that whilst a general goal of English teaching would seem logically to be an improvement in accuracy, proficiency is not addressed on intensive courses. Turner (2004) has argued that, as a result of this, learner language suffers and this is a fundamental flaw, because this can eventually impede the communication of content. Turner notes that "academic success is rarely attributed to good language use" (p. 99), but points out that whilst good language can go unnoticed, bad language is visible and creates issues. She argues that EAP instruction concentrates on the macro-level at the expense of the micro-level elements, to the eventual detriment of the student. She argues that as the manipulation of the language is key to the expression of ideas, proficiency is as equally important as knowledge of content. 


\subsection{Feedback on writing}

It would seem that the problem lies in providing learners with a balance between the general skills and knowledge which instructors and syllabus designers know are relevant to the eventual success of students as a body, and a way of accommodating the specific linguistic needs of learners. One approach which can be employed is to provide students with feedback on their writing. Whilst it is important to acknowledge that the virtue of giving feedback in the first place is disputed by some (Truscott, 1996) this is in theory a pragmatic and valid option for two main reasons. Firstly, regardless of the arguments as to whether or not feedback is effective, when a learner submits work, they usually do so expecting a response from the instructor (Yates \& Kenkel, 2002; Chandler, 2003). Secondly, it is a method in which the learner is free to expose individual linguistic issues through the formation of errors. On a pre-sessional course, this may be the only point at which the instructor is made aware of a particular student's linguistic needs.

The form that this feedback should take divides practitioners. Ferris (2002) and Sheen (2007) have advocated direct feedback for learners, particularly at a lower level. This is detailed feedback, often taking the form of providing the correct form for the student. The clear advantages of this are that the student is made aware of how their error deviated from the correct version and that there is a model made available for repetition and future use. Direct feedback becomes problematic in EAP contexts, however, because it could be seen to undermine the drive towards independent learning; the method encourages little, or indeed no, cognitive participation of the learner by engaging them with their own analysis of the error. In terms of a pre-sessional course it could also be argued that providing highly detailed feedback is not a realistic or sensible use of an instructor's limited time.

The polar opposite is indirect feedback. This consists of the instructor alerting the learner to the fact that there are errors in the text, but does not attempt in any way to reformulate any of the language. It might include circling a word to show it is incorrect but offering no other information, or simply providing a mark in the margin of the text which indicates that there is an error somewhere within that line. The rationale for this technique is that it requires thought and work on the part of the learner in analysing their own writing. The approach has obvious benefits in relation to cognitive learning and autonomy. Ferris and Roberts (2001) suggest that, in the long term, this approach is much more likely to lead to accurate language use, but reliable longitudinal evidence to support this is lacking. Again, it could be argued that in pre-sessional contexts this type of activity would be too time consuming, in this case for the learner.

A common approach which offers a compromise, although one which is generally classified as indirect rather than direct feedback, is one which uses meta-linguistic correction codes. With these, learner writing is marked up with symbols representing a series of meta-linguistic terms which the student can then examine. If they have made an error in tense, for example, the instructor might highlight the error by marking it with a ' $T$ '. This means that the student is made aware of the nature of their error, but is still obliged to perform further analysis of the language in order to perform the correction. Ferris (2006) showed that $77 \%$ of errors marked up with a correction code were revised successfully by students. Using this approach also provided data about which types of error were dealt with more or less successfully. This method also has the potential benefit of providing students with a relatively simple diagnosis of persistent error areas which might need further thought or research; a page full of 'S/Vb' annotations might highlight a fossilised issue with subject-verb agreement, for example. Whilst the results of Chandler's study into error correction methods (2003) suggested that the most effective method of correction was actually direct correction, there was a discrepancy between this result and the perception of the students, who felt that metalinguistic coding was more beneficial. A similar attitude had already been noted by Ferris and Roberts (2001), whose underling coupled with a description of the error was the method preferred by students.

\subsection{Research questions}

In summary, the short nature of pre-sessional courses means that macro-elements of organisation and academic convention are usually emphasised at the expense of individual linguistic needs and that a prevailing attitude is that these needs cannot easily be addressed in a pre-sessional context, with low expectation of tangible linguistic improvement on courses. However, error feedback on writing has been identified as an area which is (a) commonly 
expected by students and institutions and (b) practicable within a pre-sessional context. The effect of providing this feedback within a pre-sessional context has not yet been investigated, and therefore this paper seeks to address the following questions:

R1. Is there any observable improvement in written accuracy on an intensive (short) pre-sessional EGAP course?

R2. Does the use of an error correction mechanism seem to contribute towards an observable increase in written accuracy?

\section{Methodology}

\subsection{Learner and course profile}

This study was undertaken during a six-week, pre-sessional course at a British university. As such, the syllabus of the institution had to be adhered to and this took the wide-angle form detailed above. The method for observing the linguistic accuracy of the learners had to be established within the parameters of the established course framework.

The research was restricted to a small sample of 26 learners. All were mainland Chinese Mandarin speakers who had completed undergraduate degrees in mainland China. All students were going on to study post-graduate degrees in economics or management. The syllabus was based around the course textbook (Corballis \& Jennings, 2009), which was an EGAP book with reading texts drawn from a management and economics based source. The students provided the researcher with signed ethical consent forms and the study met the ethical standards of the researcher's university.

\subsection{Data collection}

The six week course consisted of 108 hours of instruction, with each week divided into ten 90 minute skills sessions and a further three 90 minute exam sessions.

In the first week, students completed a pre-course writing task which constituted the baseline text for this study. Over the remainder of the course, students completed a cycle of four essay writing tasks. Tasks were assigned on a Friday and a 300 to 400 word text submitted on the Monday. This was marked up with errors and returned on Wednesday. A revised draft was submitted on Friday. Students also worked on an independent piece of extended writing of 1,500 words. A draft was submitted in the third week of the course and comments were restricted to content, rather than feedback on individual learner errors. The baseline and extended writing allow for a comparison of pre-and post-course accuracy rates whilst the drafts and revisions enable any immediate changes in accuracy derived from teacher feedback to be observed.

At the end of the course, students completed a 12 point questionnaire marked according to a 5-point Likert scale, with questions targeting student use of feedback and their perceptions of its effectiveness (see Appendix). Two learners also agreed to short interviews in which they expanded on the areas covered by the questionnaire.

\subsection{Error Correction Method}

The metalinguistic correction chart be used with students is displayed below in Table 1. It is similar in nature to that of Ferris' (2002) sixteen point code and Jordan's (1999) twenty point code in that it attempts to cover a range of specific errors rather than grouping them into broad categories such as 'grammar' and 'vocabulary'. 
Table 1.

Summary of error codes used for feedback.

\begin{tabular}{|l|l|}
\hline Symbol & Meaning \\
\hline$T$ & TENSE \\
\hline WW & WRONG WORD \\
\hline WO & WORD ORDER \\
\hline WF & WORD FORM \\
\hline G & GRAMMAR \\
\hline F/I & APPROPRIACY / REGISTER \\
\hline$\wedge$ & WORD MISSING \\
\hline Agr & SUBJECT-VERB AGREEMENT \\
\hline P/S & NUMBER \\
\hline C/U & COUNTABLE/UNCOUNTABLE \\
\hline$?$ & SENSE/MEANING UNCLEAR \\
\hline A & ARTICLE \\
\hline
\end{tabular}

\subsection{Measuring writing proficiency in terms of accuracy}

Wolfe-Quintero et al. (1998) define written proficiency as a combination of fluency, complexity and accuracy. Fluency is measured through the production of language at a certain rate (i.e. within a given time), complexity through the variations in text structure and accuracy through the error-free production of text. These are inter-dependent and there may be "trade-offs" (Wolfe-Quintero et al., 1998, p. 39; Skehan \& Foster, 2001; Hokamura, 2018) between the three elements; an increase in fluency may be made at the expense of accuracy, for example, as the learner pays less attention to error production. Measuring the inter-dependent nature of these components was beyond the scope of this study and, as in research made by Polio (1997), Polio et al. (1998) and Storch and Tapper (2009), accuracy was used as the tool to judge the increase in written proficiency.

In order to measure accuracy, each script was analysed for number of 'TT', T-Units (Terminal Units) and number of Error-Free T-Units, (EFT), with the corresponding ratios reported as percentages. The T-Unit as defined by Hunt (1965) consists of any independent clause and its dependent clauses. Below is an example of a student produced T-Unit:

Because there are too many people looking for water, these wells becomes [sic] dry after one or two months.

In this example, because of the error in subject-verb agreement (these ... becomes), the T-unit would be classed as incorrect.

The more EFT present in the text, the more accurate the piece of learner writing. One issue brought up by Bardovi-Harlig and Boffman (1989) is the discrepancy between number of errors and number of EFT. Below is an example of student draft and revision:

If the government will increase [sic] benefits, the poverty [sic] people would suffer less.

The two errors present in the draft were corrected by the student in the revision process to the following:

If the government increases [sic], the poor would suffer less.

In the original draft, there is one T-unit which is incorrect, but two errors. In the revised version, an error has been eliminated. However, the presence of the remaining error causes the T-unit to remain classified as incorrect. That is, the entire unit of meaning had to be correct in order for the t-unit to be correct. A smaller unit of measurement, the error free clause (EFC) has been used by both Ishikawa (1995) and Hokamura (2018). However, whilst this has been deemed more suitable for lower level learners, the EFT was judged to be better for the participants in 
question as inaccuracy in one part of a clause has the potential to affect the meaning of the tunit in its entirety.

Both the identification of error types and the identification of an incorrect or error free T-unit (EFT) were subject to inter-rater reliability tests of a sample of the texts and there was no deviation in the identification of EFTs between raters.

\section{Results}

\subsection{Quantitative data from texts}

The collation of texts resulted in 26 baseline essays (cycle 1), 104 drafts (cycles 2 to 5), 104 revisions of the drafts from cycles 2 to 5 and 26 final essays (cycle 6). Table 2 summarises the compositions at each stage in terms of total T-units (TT) in the text, error free T-units in the draft (EFT), and for cycles 2 to 4, which were texts the students received coded error feedback on, error free T-units in the revision (EFT REV). The mean and s.d. values refer to TT/EFT per student text at each stage.

\section{Table 2.}

Summary of Total T-units (TT) and Error Free T-Units (EFT).

\begin{tabular}{|c|c|c|c|c|c|c|c|c|c|c|c|c|c|c|c|c|}
\hline \multirow[t]{2}{*}{ Stage } & \multicolumn{2}{|c|}{ Baseline (1) } & \multicolumn{3}{|c|}{ Cycle (2) } & \multicolumn{3}{|c|}{ Cycle (3) } & \multicolumn{3}{|c|}{ Cycle (4) } & \multicolumn{3}{|c|}{ Cycle (5) } & \multicolumn{2}{|c|}{ Final (6) } \\
\hline & TT & EFT & TT & EFT & $\begin{array}{l}\text { EFT } \\
\text { REV }\end{array}$ & TT & EFT & $\begin{array}{l}\text { EFT } \\
\text { REV }\end{array}$ & TT & EFT & $\begin{array}{l}\text { EFT } \\
\text { REV }\end{array}$ & TT & EFT & $\begin{array}{l}\text { EFT } \\
\text { REV }\end{array}$ & TT & EFT \\
\hline Total (n) & 384 & 75 & 372 & 75 & 270 & 400 & 158 & 328 & 404 & 164 & 329 & 316 & 155 & 265 & 1760 & 894 \\
\hline$\%$ & - & 19.53 & - & 20.16 & 72.58 & - & 39.5 & 82 & - & 40.59 & 81.44 & - & 49.05 & 83.86 & - & 50.8 \\
\hline Mean & 14.7 & 2.9 & 14.31 & 2.9 & 10.39 & 15.4 & 6.08 & 12.61 & 15.54 & 6.31 & 12.65 & 12.15 & 5.96 & 10.19 & 67.69 & 34.38 \\
\hline S.D. & 3.81 & 2.37 & 3.21 & 2.45 & 3.51 & 4.43 & 3.01 & 4.27 & 3.02 & 2.84 & 4.16 & 5.33 & 3.96 & 5.02 & 15.64 & 14.3 \\
\hline
\end{tabular}

From the baseline to the text produced in cycle 5, length of compositions in terms of total Tunits remained similar. Mean averages range only from 12.15 TT to 15.54 TT. The large increase in total T-units at the final stage reflects the increased length of the text the students were required to produce. The key information with regard to the research questions is to be found in the production of EFT at different stages. The mean average of EFTs across the drafts, cycles 1 to 5, shows a gradual, though not entirely consistent, increase in the rates of accuracy at the draft stage, ranging from an average of 2.9 EFT in the drafts at stages 1 and 2, rising to a peak of 6.31 and finally falling slightly to an average of just under 6 EFT. The final stage shows that the average number of EFT rose to slightly over 34 , but again this simply reflects the comparatively extensive length of the final text. The revisions to the drafts in cycles 2 to 5 show a consistent increase in accuracy, with the average EFT count being approximately twice that of the drafts in cycles 3 to 5 and three times that of the draft in cycle 2. The increase suggests (a) that students were making corrections based on the feedback and that (b) these were largely successful. The increased accuracy rates in student writing at each stage and across the course are summarised more succinctly in the figure 1 below. 
Figure 1.

Accuracy rates in terms of percentage of Error Free T-Units (EFT) within texts.

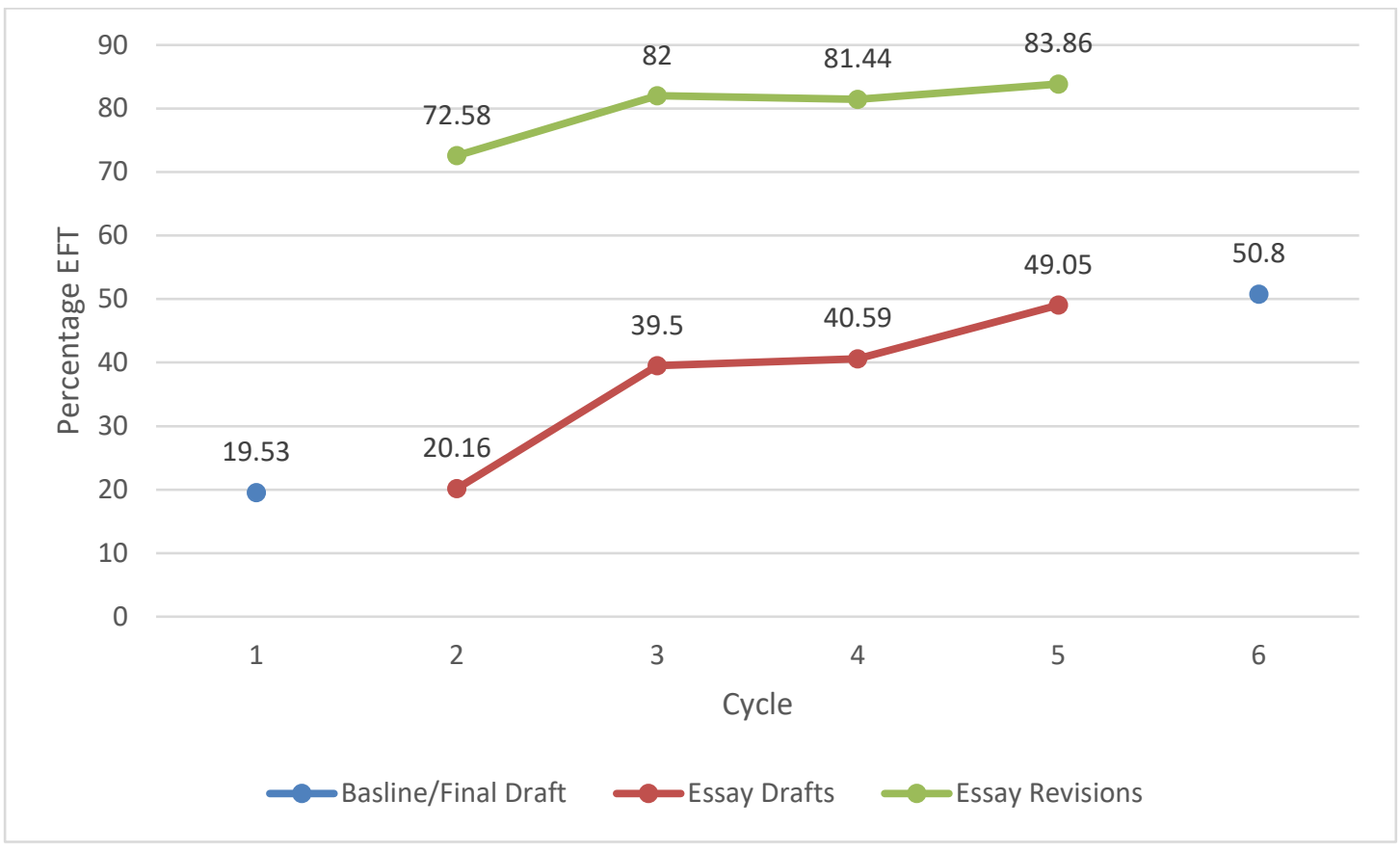

The increased level of accuracy between drafts and revisions is immediately obvious. This at least suggests that the method of feedback employed was effective in raising awareness of errors and eliciting a response from the learners. It also suggests that the use of the metalinguistic coding is an appropriate method of feedback, as accuracy of the revised texts increased by between $34 \%$ and $52 \%$. Though this finding answers R2 and suggests that the use of an error correction mechanism seem to contribute towards an observable increase in written accuracy, this is limited to discrete points of revision. It is perhaps not surprising that a revised version of a draft which has been commented on represents an improvement.

Of more import is the accuracy at each of the draft cycles themselves. There is clearly an increase in the proportion of EFTs being produced and whilst from cycle to cycle there is some fluctuation, the overall trend appears to be one of increased written accuracy. From cycle 2 to 5 (i.e., the drafts subject to feedback produced subsequent to the baseline), accuracy increased by nearly $30 \%$. A repeated measures ANOVA examining the accuracy rates between drafts 1 and 4 suggested the mean scores for EFTs at each draft stage were statistically significantly different $(F(3 / 75)=9.345, p<0.001)$.

To address research question 1 (Is there any observable improvement in written accuracy on an intensive (short) pre-sessional EGAP course?), a paired samples T-test on baseline and final texts was conducted. The results from the pre-test $(M=2.88, S . D=2.37)$ and post-test $(M$ $=16.2$, S.D = 14.31), measuring the frequency of error free t-units in students' texts, indicate that the course resulted in an improvement in written accuracy $(\mathrm{t} 25)=-11.21, \mathrm{p}<.001$.

\subsection{Qualitative data from learners}

Surveys conducted with learners at the end of the course indicated in a positive perception of the error-correction process. Just under $77 \%$ of learners were already in the habit of checking the feedback that teachers provided on written work, which itself strengthens the arguments mentioned earlier in section 1.2 (Yates \& Kenkel, 2002; Chandler, 2003) that feedback is expected by learners. $79 \%$ of students reported that in the past they tried to respond to feedback their teachers provided. There was a slight rise to $85 \%$ of students saying they now responded to the feedback. $77 \%$ of students felt that the feedback mechanism had made them more aware of their errors, but were less confident, at just over a $60 \%$ positive response, that 
the mechanism had helped them in lowering the numbers of errors they initially produced. The students also seemed to be more ambivalent about whether or not the amount of time taken to study and respond to the feedback was beneficial, with less than $40 \%$ making an affirmative response. It seems from these responses that the error feedback mechanism is a plausible way of raising awareness of errors though they reiterate the issue, as does the quantitative data, as to what extent feedback influences subsequent production.

Though the student interviews were limited to two subjects, two points were illuminating. When asked about how their writing had changed over the course, student $Y$ connected the increased awareness of errors directly with a change in their writing, stating:

First of all, I used to write long sentences before I came here, but I don't really care whether it's right or wrong, just I prefer to write long sentences. But when I came here I found it's not necessary. The more I focus on is the corrections. So this expose many mistakes so it's not good. So I start prefer pay attention to the grammar and more exact meaning what I want to express.

Both students consistently mentioned grammar and vocabulary as things which they wanted help with (not organisation) and student said $Z$ made a comment which highlighted the importance of the issue raised in the introduction, that of balancing the organisational aspect of writing with a method of assisting learners with their individual linguistic needs, and echoes Turner's (2004) observations:

I think the most difficult part is how to write more academic and the word and vocabulary we use cannot use some colloquial ones and I think it's the most difficult part...some other parts like the structures I think is not so difficult for me because we know how to organise our mind and how to organise the structures but I think the most difficult one is the vocabulary. Sometimes I know what I mean and I know what I am going to say but I cannot express myself well.

\section{Discussion}

Research question 1 asked if there is any observable improvement in written accuracy on an intensive (short) pre-sessional EGAP course. The results of this study suggest that there was a beneficial course effect, with average increased written accuracy of approximately $30 \%$ between the start and the end of the course. Tangible increases in written accuracy were also present at each draft stage indicating potential benefits of the feedback process on subsequent new texts. This is contrary to the impression and expectations of many practitioners (Basturkmen \& Lewis, 2002) and raising awareness of the potential for short courses to help develop written accuracy could benefit institutional approaches towards course planning and teaching outcomes. Learners in the study certainly had expectations that the micro-elements of their writing would improve, as evinced by the time they were willing to spend focusing on corrections and attempting to eliminate errors. It would be well for these expectations to be borne in mind when devising syllabi which might otherwise be wide-angle in aspect.

Research question 2 asked if the error correction method contributed towards any observable increase in written proficiency. That learners were responding to the feedback most of the time supports the views of Yates and Kenkel (2002) and Chandler (2003) that producing error feedback for learners is an important part of writing instruction. The increase in EFTs both at the revision stage and, to a lesser extent in their drafts, also corroborates the assertions that, when learners have their errors pointed out to them, they can make successful corrections (Gass \& Selinker, 1983; Makino, 1993).

Providing an arena for linguistic focus through the draft/feedback/revision cycle meant that specific aspects of the language related to a particular learner could be addressed without infringing on the time needed for other types of input during the lessons. Employing this method as part of a pre-sessional course seems justified in having some potential to address the lack of emphasis on accuracy and written proficiency which is bemoaned by Turner (2004) as a 
possible cause of problems regarding content and expression later in academic life. If so, then error correction also has a place in contributing towards the goals of EAP courses in equipping learners with the necessary tools for further academic study (Alexander et al., 2008).

\section{Limitations and further research}

The difficulty of discriminating between the effect of the feedback cycle and other variables, such as input from classes and the interlingual stages of the learners, is a factor which needs to be taken into account in the observation of these results. Hokamura (2018) has pointed out the importance of acknowledging the longitudinal, individual and unpredictable aspects of language development. Further, this study was limited to a small sample size and the participants were all of a similar nature with regard to their L1, learning and cultural background and short-term academic aspirations. Given that classes on pre-sessional courses often have a greater variety in their composition, it would be of interest to see if similar results could be observed within different teaching contexts.

Whilst the meta-linguistic error correction method shows an effectiveness level in keeping with other studies (Ferris, 2006), other types of feedback may also show a positive effect. Interventions through direct feedback (Ferris, 2002; Sheen, 2007) or indirect feedback (Ferris \& Roberts, 2001) could also be investigated. The research presented here formed the basis for a subsequent experimental investigation into the treatment of different error types and certainly more understanding is needed of how effective feedback is for learners.

The role and attitude of the instructor on short courses is also an area which could be examined. Just as short courses place the learners under pressure, so the time constraints are felt by the teachers. Comprehensive error highlighting can be a time-consuming activity and, if teachers were expected to engage in a full round of draft and revision marking as conducted within this study, there may be a detrimental effect on the time they can allocate to other areas, such as planning lessons, and subsequent issues with stress and motivation.

Finally, in measuring only accuracy within this study, I am of course only highlighting part of the picture of the learners' linguistic development. Examining the relationship between fluency, accuracy and complexity would be an interesting point for further research as it would give a more holistic view of learners' ability to write proficiently.

\section{Conclusion}

The wide-angled aspect of short pre-sessional courses is a convention which is unlikely to change due to a number of factors, chief amongst which are time limitations and institutional requirements. Macro-features such as organisational aspects are likely to continue to be the focus of most programmes. However, the observations made here suggest that this does not necessarily need to be at the expense of linguistic proficiency and that certain interventions, in this case feedback on written errors, can help to address the specific language needs of learners. 


\section{References}

Alexander, O., Argent, S., \& Spencer, J. (2008). EAP essentials: A teacher's guide to principles and practice. Garnet Publishing.

Archibald, A. (2001). Targeting L2 writing proficiencies: Instruction and areas of change in students' writing over time. International Journal of English Studies, 1(2), 153-174.

Banarjee, J., \& Wall, D. (2006). Assessing and reporting performances on pre-sessional EAP courses: Developing a final assessment checklist and investigating its validity. Journal of English for Academic Purposes, 5(1), 50-69.

Bardovi-Harlig, K., \& Bofman, T. (1989). Attainment of syntactic and morphological accuracy by advanced language learners. Studies in Second Language Acquisition, 11, 17-34.

Basturkmen, H., \& Lewis, M. (2002). Learner perspectives of success in an EAP writing course. Assessing Writing, 8(1), 31-46.

Bruce, I. (2011). Theory and concepts of English for Academic Purposes. Palgrave Macmillan.

Burgess, J., \& Etherington, S. (2002). Focus on grammatical form: Explicit or implicit? System, $30,433-458$.

Chandler, J. (2003). The efficacy of various kinds of error feedback for improvement in the accuracy and fluency of L2 student writing. Journal of Second Language Writing, 12, 267-296.

Cho, Y. (2003). Assessing writing: Are we bound by only one method? Assessing Writing, 8(3), 165-191.

Corballis, T., \& Jennings, W. (2009). English for Management Studies in Higher Education Studies. Garnet Publishing.

Department for Business, Innovation \& Skills. (2013). International education: Global growth and prosperity. HM Government.

https://www.gov.uk/government/publications/international-education-strategy-globalgrowth-and-prosperity

Ferris, D. (2006). Does error feedback help student writers? New evidence on the short-andlong term effects of written error correction. In K. Hyland \& F. Hyland (Eds.), Feedback in second language writing: Context and issues (pp. 81-104). Cambridge University Press.

Ferris, D. (2002). Treatment of error in second language student writing. University of Michigan Press.

Ferris, D., \& Roberts, B. (2001). Error feedback in L2 writing classes: How explicit does it need to be? Journal of Second Language Writing, 10(3), 161-184.

Gass, S. M., \& Selinker, L. (1983). Language transfer in language learning. Newbury House Publishers.

Gillett, A. J. (2011). What is EAP? http://www.uefap.com/bgnd/whatfram.htm

Hamp-Lyons, L., \& Heasley, B. (2006). Study writing: A course in writing skills for academic purposes. Cambridge University Press. 
Hartshorn, J., Evans, N., Merrill, P., Sudweeks, R., Strong-Krause, D., \& Anderson, N. (2010). Effects of dynamic corrective feedback on ESL writing accuracy. TESOL Quarterly, 44(1), 85-109.

Higher Education Statistics Authority. (2019). Where do HE students come from? HESA. https://www.hesa.ac.uk/news/17-01-2019/sb252-higher-education-studentstatistics/location

Hokamura, M. (2018). The dynamics of complexity, accuracy and fluency: A longitudinal case study of Japanese learners' English writing. JALT Journal, 4O(1), 23-46.

Hunt, K. (1965). Grammatical structures written at three grade levels. National Council of Teachers of English.

Hyland, K. (2009). Academic discourse. Continuum.

Ishikawa, S. (1995). Objective measurement of low-proficiency EFL narrative writing. Journal of Second Language Writing, 4, 51-69.

Jordan, R.R. (1999). Academic writing course. Pearson Longman.

Makino, T. (1993). Learner self-correction in EFL written compositions. ELT Journal, 47(4), 337-341.

Polio, C. (1997). Measures of linguistic accuracy in second language writing research. Language Learning, 47(1), 101-143.

Polio, C., Fleck, C., \& Leder, N. (1998). "If I only had more time": ESL learners' changes in linguistic accuracy on essay revisions. Journal of Second Language Writing, 7(1), 4368.

Sheen, Y. (2007). The effect of focused written corrective feedback and language aptitude on ESL learners' acquisition of articles. TESOL Quarterly, 41(2), 255-283.

Skehan, P., \& Foster, P. (2001). Cognition and tasks. In P. Robinson (Ed.), Cognition and second language instruction (pp. 183-205). Cambridge University Press.

Storch, N., \& Tapper, J. (2009). The impact of an EAP course on postgraduate writing. Journal of English for Academic Purposes, 8, 207-223.

Swales, J. M. (2005). Genre analysis (2nd ed.). Cambridge University Press.

Truscott, J. (1996). The case against grammar correction in L2 writing classes. Language Learning, 46(2), 327-369.

Turner, J. (2004). Language as academic purpose. Journal of English for Academic Purposes, 3, 95-109.

Watson-Todd, R. (2003). EAP or TEAP? Journal of English for Academic Purposes, 2, 147156.

Widdowson, H. G. (1983) Learning purpose and language use. Oxford University Press.

Wolfe-Quintero, K., Inagaki, S., \& Kim, H.-Y. (1998). Second language development in writing: Measures of fluency, accuracy and complexity. University of Hawai'i Press.

Yates, R., \& Kenkel, J. (2002). Responding to sentence-level errors in writing. Journal of Second Language Writing, 11, 29-47. 


\section{Appendix: Exit survey questions}

\begin{tabular}{|l|l|}
\hline 1 & IN THE PAST, I always checked my written work before I gave it to my teacher \\
\hline 2 & IN THE PAST, I always read the notes my teacher gives me about my errors \\
\hline 3 & IN THE PAST, I always tried to correct my drafts \\
\hline 4 & NOW, I always check my written work before I give it to my teacher \\
\hline 5 & NOW, I always read the notes my teacher gives me about my errors \\
\hline 6 & NOW, I always try to correct my drafts \\
\hline 7 & Correcting my work helped me recognize my errors \\
\hline 8 & Correcting my work helped me reduce the number of errors I made \\
\hline 9 & Correcting my work helped me learn grammar \\
\hline 10 & Correcting my work helped me learn vocabulary \\
\hline 11 & Correcting my work took too much time \\
\hline 12 & The teacher's feedback on my errors was easy to understand \\
\hline
\end{tabular}

Response range: Strongly agree/ Agree / Undecided / Disagree / Strongly disagree 